\title{
HUMAN-COMPUTER INTERACTION IN E-NEGOTIATION
}

\section{Gordana Dobrijević, Jelena Đorđević Boljanović, Ivana Brdar}

Singidunum University, 32 Danijelova Street, Belgrade, Serbia

\begin{abstract}
:
Even though we think about negotiation as an essentially human activity, there are many negotiation support systems and automated agents developed for helping human negotiators. They can support or completely replace human negotiators, and serve as intermediaries for individuals or organizations. Some of them can even take into consideration cross cultural differences between people. In this paper, we address some of the issues related to interaction and synergy between human negotiators and automated negotiation agents.
\end{abstract}

Key words:

e-negotiations, automated negotiation agents, human-agent interaction.

\section{INTRODUCTION}

Extensive use of the Internet has radically altered the way we use computers. Today, it is common for people and computers to work together, including over great distances in time and space. For instance, we can see computer systems as parts of military systems, online auctions, emergency response systems ("Colored Trails", n.d.) and negotiations. Although we think about negotiation as a predominantly human activity, there are many negotiation support systems (NSS) and automated agents developed for helping human negotiators, e.g. INSPIRE, Virtual Human Agent, or Diplomat. Software can also be used in human-to-human negotiation analysis to predict negotiation outcome in early stages of the process.

Since the 1990-ies, two-thirds of the research of the NSSs have focused on operational level problems, NSS technologies, processes and methods (Pervan and Arnott, 2013). On the other hand, comparatively little research has been dedicated to the interaction between negotiation agents and human negotiators (Lin and Kraus, 2012). Human-agent interaction is especially important, because negotiation agents can play different roles in electronic negotiations. They can support or completely replace human negotiators, serve as intermediaries for individuals or organizations, e.g. bidding in online auctions (van Wissena et al., 2012), or as a training tool (Dobrijević and Đorđević Boljanović, 2014).

Negotiation is a process that happens to all of us, almost daily, and sometimes we are not even aware of it. Designing an efficient automated agent could relieve people of the tasks that can be performed by machines, 
e.g. brokering agents. Some of the benefits of using fully automated agents instead of human decision makers are: better outcomes, fewer conflicts and lower costs, because less work is done by humans (Yang et al., 2012) and normally negotiations take less time. However, semantic and emotional issues involved in negotiations make human negotiators indispensable when negotiating about more important or complex matters, so a human-agent cooperative system is needed (Hindriks and Jonker, 2008).

\section{AUTOMATED TEXT CATEGORIZATION IN HUMAN-TO-HUMAN NEGOTIATIONS}

The study of Kesting and Smolinski (2013) showed that in e-negotiations people have less trust towards the other party, that the relationships are on a lower level than in face-to-face negotiations, and that people are more prone to hard and distributive negotiation style. This is probably due to perceived informality and anonymity, and the lack of nonverbal communication. That is in accordance with several earlier studies (2010) which showed that communication media have important effect on negotiation process and outcome. Researchers tried to determine how the communication process during negotiations actually influences the effectiveness of negotiations. Those analyses were performed manually, which is laborious and time-consuming.

Social Information Processing Theory (Walther and Parks, 1992, ac cited in Körner and Schoop, 2013) proposes that social cues (responsible for building trust and understanding between the parties), in the absence of nonverbal communication while communicating via email, are transferred directly through words. In order to facilitate this analysis, Sokolova and Szpakowicz (2007) used text mining (Statistical Natural Language Processing and Machine Learning techniques) to find general tendencies in the text. They performed their research based on the data acquired from the negotiation support system INSPIRE during several years. The outcomes were labeled either as successful or unsuccessful, and the participants were either buyers or sellers. They focused on the words that show negotiator's desire to come closer or to move away from the other party, as well as the words showing power (or the lack of it). More than 1,500,000 words were used during the analysis. They concluded that language symbols can predict negotiation outcomes early in the process.

The subsequent study of Sokolova and Lapalme (2010) confirmed those findings and showed that successful e-negotiations contain more positive language and emotions than the unsuccessful ones (although the analysis of negative emotions did not have conclusive results). This study also showed that informativeness (the amount of provided information) of the messages between the participants corresponds to the negotiation success. However, Körner and Schoop (2013) were not able to reproduce these results in a later experiment. As the authors said themselves, it is probably due to the nature of the negotiation data and methodological problems.

\section{SOME ISSUES IN HUMAN-AGENT INTERACTION}

Since people come from different backgrounds, and have different characteristics, efficient agents should be able to take these variables into consideration when negotiating with different people. People make mistakes; human behavior is varied and is influenced by cultural, social and cognitive factors (Lind and Kraus, 2012). For this reason, automated agents are increasingly using heuristic methods (rules of thumb that allow for deviations of human behaviour, which produce adequate results, and not the best possible) (Dobrijević, and Đorđević Boljanović, 2014). Some other models used for creating negotiation strategies are Bayesian models, generic algorithms, and estimation algorithms for multi-issue trade-offs (Yang et al., 2012).

Shahmoradi et al. (2014) proposed a new agentbased model for simulating negotiations. They included a cultural parameter of time sensitivity in order to help intelligent agents in cross-cultural negotiations in B2C e-commerce context. The seller's offers are based on the buyer's predicted time sensitivity in product delivery. The simulations are based on different cultural data sets of five countries. Their results showed that this model could decrease the number of negotiation rounds and the total time spent.

Also, it is difficult to design generic automated negotiation agents that can negotiate in various areas. Sometimes it is because of the characteristics of the area itself, and sometimes it is because there are many preferences negotiators can have as well as various strategies and tactics they can use. That is why many agents are created as area-specific and cannot be used in other domains (Lin et al., 2014).

Another issue is evaluating agent-human interaction. It is a critical part of the designing process, because it shows how successful the automated negotiating agents are (Lin at al., 2012). As system and agent behaviour is 
impossible to anticipate, this evaluation is normally done through simulations and observational analysis (Baarslag et al., 2010). Since that process requires time and effort, Lin and Kraus (2012) have devised two environments to make it easier and more manageable: GENIUS (which stands for "General Environment for Negotiation with Intelligent multi-purpose Usage Simulation") environment and Colored Trails game environment. They can be used for testing automated agents, as well as evaluating human-human, agent-human, and agent-agent interactions. Genius can also be used to prepare human negotiators through negotiations against other people or software agents, and to train software developers to create generic automated agents (Baarslag et al., 2010). Colored trails ("Colored trails", n.d.) environment enables exploration of human decision-making as well as computational strategies. They can be studied in groups consisting only of people or in mixed groups of humans and computer systems.

In their experiment of agent-human negotiations, Vahidov and Kersten (2012) paired different types of agents with humans in negotiating a product sale. The results were quite interesting: the majority of participants were not sure if they had been negotiating with agents or humans, while very small number of participants guessed accurately that they had been negotiating with software agents. Even in the case of human to human negotiations, 2 out of 30 participants thought they had been negotiating with a computer (!). The answers actually depended on the type of strategy used. If distributive and then integrative strategy was used (more complex pattern of concession making), then the majority of participants thought they were negotiating with a human. In this experiment software agents performed better than humans, in both utility and number of agreements reached.

Experiments with human subjects are needed to evaluate how successful automated agents are in negotiating with people. That, as we said, can be expensive and it takes time. Seeing that automated agents and humans behave differently, the issue is whether other sorts of computer agents can be used to evaluate automated negotiators. One method of this evaluation is the use of Peer Designed Agents (PDAs), created by human subjects (Lin et al., 2012). The design of the PDAs involves human subjects to state their preferences for all sets of information in the game (and not only those that can appear during the game). Some previous studies (Chalamish et al., 2008, as cited in Lin et al., 2012) showed that agents designed by human subjects can sometimes be used instead of humans in some games.
Lin et al. (2012) carried out bilateral negotiation simulations with more than 300 human negotiators and 50 PDAs in two different environments: one was simulating real-life transactions and the other was Colored Trails game. In order to make situations more life-like, other party's preferences were not disclosed. People negotiated with other people, with PDAs, and with negotiating agents (KBAgent and QOAgent).The authors investigated whether PDAs behaved like humans and whether they can be used instead of people in the evaluation of negotiating agents. They found out that automated agents were more successful than PDAs in the same negotiation scenario where they were more successful than humans, and that generally they were equally generous to the other party. They also showed that, although a bigger part of the evaluation can be done without humans, they are still necessary in the final evaluation.

\section{THE LATEST ADVANCES}

Automated agents are getting better in various respects. Many of the current agent strategies consist of different modules. The strategy is an outcome of various combinations of these modules, with different success of each module. For example, an agent could have a module that has excellent results in predicting preferences of the other party, but still have bad results because it concedes too fast. So far, there is no way to determine which of the components is crucial in reaching negotiation success. In order to examine the efficiency of the individual factors of negotiation strategy, Baarslag et al. (2014) proposed an architecture that differentiates three elements which together create negotiation strategy, namely the bidding strategy, the opponent model, and the acceptance condition (BOA). They claim that the existing agents are compatible with the proposed architecture. Based on e.g. target sum, time, and discount, the bidding strategy establishes the concessions that could be made. An opponent model shows preferences of the other party; while the acceptance condition says whether the opponent's bid is acceptable or not. Separating the individual components, the authors were able to recognize some opponent models that are more efficient than others; and to replace existing opponent models with others, in order to improve their performance. Recombining the components enabled them to considerably improve the negotiating agents' performance.

Since 2010, there have been five competitions of automated negotiating agents. The aim of this competition is to improve the "research in bilateral multi-issue 
closed negotiation" (“Tudelft Negotiation", n.d.). Closed negotiation happens when parties do not disclose their preferences, and it takes place quite often in life. Here we see the importance of using heuristic models, because negotiation agents do not have sufficient information about the other party. This competition is based on the GENIUS environment (Baarslag et al., 2010). This competition should help create more proficient negotiating agents, test bargaining strategies, examine opponent models, and especially gather negotiation agents, domains and preference profiles, so that researchers and academics could use them widely (Baarslag et al., 2010).

Artificial intelligence can help human negotiators in many ways, e.g. implementing search techniques or using strategic reasoning. On the other hand, it cannot help with the issues such as small talk that humans engage in during the process, and obtaining common knowledge related to the field in question. The idea is to reach synergy between negotiation agents and humans, neutralizing each other's weaknesses and taking advantage of strengths. While humans can understand emotional tone and context of negotiation, they need support in neutralizing emotions and focusing on their interests (Jonker et al., 2012).

According to Hindriks and Jonker (2008), in order for humans to cooperate with machine, they need to share an abstract model of a particular task (i.e. negotiation), detailed models of a specific domain (e.g. salary negotiations), the user model, and the opponent model - jointly called the DUO models. They can be shared only if they imitate cognitive models of the humans. Hindriks and Jonker (2008) proposed a task division between the human user and the machine, based on strengths and weaknesses of both. They developed a negotiation model matching human perception of negotiations, called Pocket Negotiator. It can work on a handheld device or a computer to help human negotiators (Figure 1-3). Pocket Negotiator can help humans with some of the most prominent challenges in negotiations, namely ignoring a potential for a win-win deal, making too big concessions, rejecting a better offer, and settling for an outcome worse than the best alternative (BATNA). It supports human negotiators during all four stages of negotiations (preparation (Figure 1), exploration (Figure 2), bidding (Figure 3), and closure). Through this human-software synergy, some usual mental errors can be prevented and user's cognitive tasks can be easier to perform.

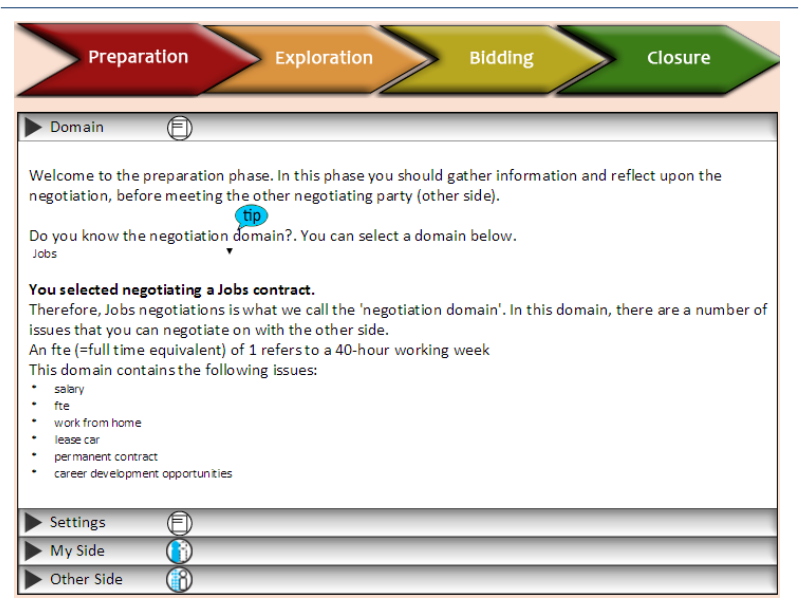

Figure 1. Pocket Negotiator software, preparation phase

Source: Pocket Negotiator (n.d.) retrieved from http://ii.tudelft. nl:8080/PocketNegotiator/index.jsp February 9, 2016

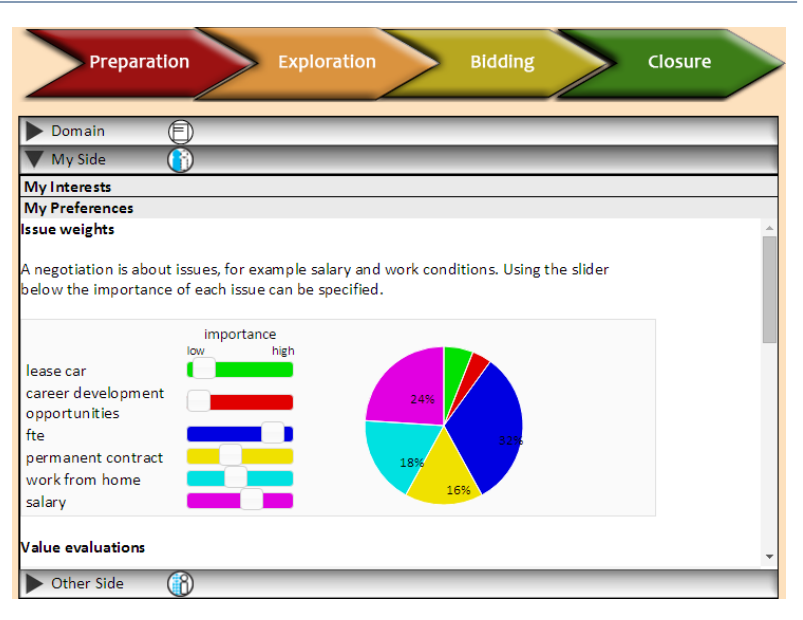

Figure 2. Pocket Negotiator software, exploration phase

Source: Pocket Negotiator (n.d.) retrieved from http://ii.tudelft. nl:8080/PocketNegotiator/index.jsp February 9, 2016

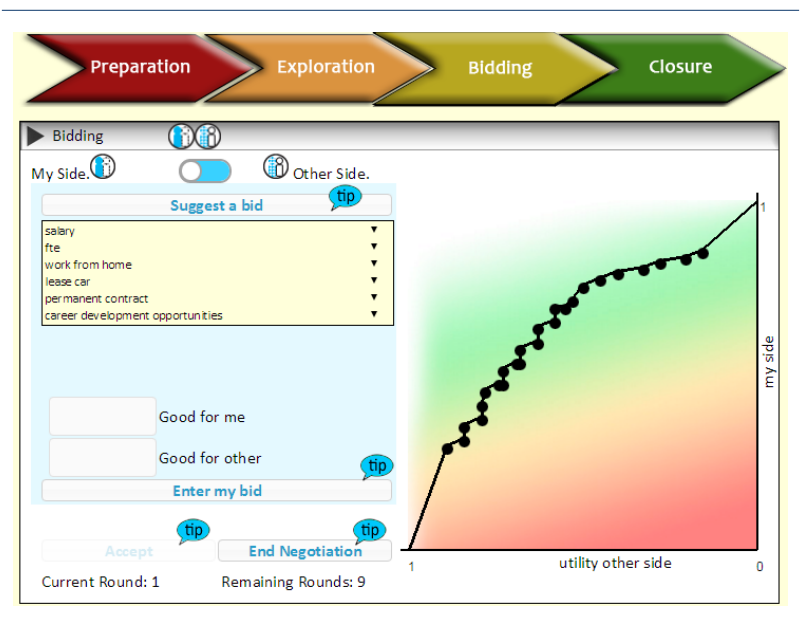

Figure 3. Pocket Negotiator software, bidding phase 


\section{CONCLUSION}

What lies ahead is difficult to predict, but we can definitively envision some new breakthroughs in the design and use of artificial intelligence in negotiation, namely automated agents and negotiation support systems. Some of the important issues in human-machine interaction were addressed in this paper, together with some contemporary solutions to the challenges of this interaction. Negotiation is an emotional process, and computers can help human negotiators cope with its complexity.

\section{REFERENCES}

Baarslag, T., Hindriks, K., Jonker, C., Kraus, S.\& Lin, R. (2010). The First Automated Negotiating Agents Competition (ANAC 2010). In Ito, T., Zhang, M., Robu, V., Fatima, S. \&Matsuo, T. (Eds.) New Trends in Agent-Based Complex Automated Negotiations, Studies in Computational Intelligence, Volume 383 (113-135). Berlin Heidelberg: Springer.

Baarslag, T. Hindriks, K., Hendrikx, M., Dirkzwager, A. \&Jonker, C. (2014) Decoupling Negotiating Agents to Explorethe Space of Negotiation Strategies. In Marsa-Maestre, I., Lopez-Carmona, M.A., Ito, T., Zhang, M., Bai, Q., Fujita, K. (Eds.) Novel Insights in Agent-based Complex Automated Negotiation, Studies in Computational Intelligence, Volume 535 (61-108). Tokyo: Springer. ISBN 978-4-431-547587 (eBook), DOI 10.1007/978-4-431-54758-7

Colored Trails (n.d.). retrieved from https://coloredtrails. atlassian.net/wiki/display/coloredtrailshome/ What+is+Colored+Trails February 10, 2016.

Dobrijević, G. \& Đorđević Boljanović, J. (2014). Negotiation Goes High Tech: Can You Negotiate With a Machine? Sinteza 2014, conference proceedings (pp. 249-253). DOI: 10.15308/sinteza-2014-249-253. Beograd: Singidunum University.

Hindriks, K. V. \& Jonker, C.M. (2008). Creating HumanMachine Synergy in Negotiation Support Systems: Towards the Pocket Negotiator, HuCom '08 Proceedings of the 1st International Working Conference on Human Factors and Computational Models in Negotiation. Delft, Netherlands - December 08 - 09, 2008 (pp.47-54), ISBN: 978-90-813811-16 doi $>10.1145 / 1609170.1609176$. New York, NY: ACM.

Jonker,C.M., Hindriks, K.V., Wiggers, P. \& Broekens J. (2012). Negotiating Agents, AI Magazine 33(3). pp. 79-91.

Kesting, P. \& Smolinski R. (2013). Starting from Scratch: A multi-stage analysis of remote e-negotiations.
Group Decision and Negotiation (GND) 2013, International Conference Proceedings, Stockholm, Sweden, June 17-20, 2013, pp.221-222. Stockholm, Sweden: University of Stockholm.

Körner, M. \& and Schoop, M. (2013) Text Mining and Electronic Negotiations - Methodological Issues and Challenges, Group Decision and Negotiation (GND) 2013, International Conference Proceedings, Stockholm, Sweden, June 17-20, 2013, pp. 238240, Stockholm, Sweden: University of Stockholm.

Lewicki, R.J., Saunders, D.M. \& Barry, B. (2010) Negotiation, international edition. Singapore: McGraw-Hill.

Lin, R. \& Kraus, S. (2012). From Research to Practice: Automated Negotiations with People. In Krüger, A. \&Kuflik, T. (Eds.) Ubiquitous Display Environments (pp. 195-212). Berlin Heidelberg: Springer-Verlag.

Lin, R., Kraus, S., Baarslag, T., Tykhonov, D., Hindriks, K. \& Jonker, C. (2014). GENIUS: an integrated environment for supporting the design of generic automated negotiators. Computational Intelligence 30(1) 48-70. available from http://onlinelibrary.wiley. com/journal/10.1111/\%28ISSN\%291467-8640, accessed February 5, 2016. DOI: 10.1111/j.14678640.2012.00463.x

Lin, R. Oshrat, Y. \& Kraus, S. (2012). Automated Agents That Proficiently Negotiate with People: Can We Keep People Out of the Evaluation Loop. In Ito, T., Zhang, M., Robu, V., Fatima, S. \&Matsuo, T. (Eds.) New Trends in Agent-Based Complex Automated Negotiations, Studies in Computational Intelligence, Volume 383 (57-80). Berlin Heidelberg: Springer.

Pervan, G. \& Arnott, D. (2013). Group and Negotiation Support Systems Research from 1990 to 2010, Group Decision and Negotiation (GND) 2013, International Conference Proceedings, Stockholm, Sweden, June 17-20, 2013, pp. 168-178. Stockholm, Sweden: University of Stockholm.

Pocket Negotiator (n.d.) retrieved from http://ii.tudelft. nl:8080/PocketNegotiator/index.jsp February 9, 2016

Shahmoradi, H., Nassiri-Mofakham, F., \& Nemati, F. (2014). Cross-Cultural Time Sensitivity in a Bilateral E-Negotiation System. New Marketing Research Journal Special Issue, pp. 55-68.

Sokolova, M. \& Lapalme, G. (2010). How Much Do We Say? Using Informativeness of Negotiation Text Records for Early Prediction of Negotiation Outcomes, Group Decision and Negotiation 21,363379. Springer Science and Business Media. DOI 10.1007/s10726-010-9211-9

Sokolova, M. \& Szpakowicz, S. (2007). Strategies and language trends in learning success and failure of negotiation, Group Decision and Negotiation 16, 469-484. DOI 10.1007/s10726-007-9083-9 
Tudelft negotiation (n.d.).retrieved from http://mmi. tudelft.nl/negotiation/index.php/Automated_Negotiating_Agents_Competition_\%28ANAC\%29 February 10, 2016.

Vahidov, R., \& Kersten, G.E. (2012). Design of software agent-populated electronic negotiation system and evaluation of human-to-agent negotiations. Interneg Research Papers INR09/12, 2012. InterNeg Research Center, John Molson School of Business, Concordia University. Available from http://interneg.concordia.ca/index.php?id=paper, accessed February 5, 2016. van Wissena, A., Galb, Y., Kamphorstd, B.A. \& Dignume, M.V. (2012) Human-Agent Teamwork in Dynamic Environments, Computers in Human Behavior 28(1), 23-33. DOI:10.1016/j.chb.2011.08.006

Yang, Y., Singhal, S. \& Xu, Y. (2012).Alternate strategies for win-win seeking agent in agent-human negotiations. Journal of Management Information Systems [serial online] 29(3), pp. 223-256, Winter 2012. Available from: Business Source Premier, Ipswich, MA, accessed January 31, 2014. 